\title{
African experiences of laparoscopic hysterectomy about a continuous series of 52 cases by the same practitioner: indications, surgical procedures and complications
}

\author{
Koffi Abdoul Koffi*, Kacou Edele Aka, Minata Fomba, Konan Seni, \\ Apollinaire Horo, Mamourou Kone
}

Department of Obstetrics and Gynecology, University Hospital of Yopougon Abidjan, Côte d'Ivoire

Received: 02 January 2018

Accepted: 31 January 2018

*Correspondence:

Dr. Koffi Abdoul Koffi,

E-mail: kkoffiabdoul@yahoo.fr

Copyright: () the author(s), publisher and licensee Medip Academy. This is an open-access article distributed under the terms of the Creative Commons Attribution Non-Commercial License, which permits unrestricted non-commercial use, distribution, and reproduction in any medium, provided the original work is properly cited.

\begin{abstract}
Background: Laparoscopy is a modern surgical technique that began in 1940 with Raoul Palmer. The present study aimed to analyse the results of a fifty-two-laparoscopic hysterectomy performed.

Methods: A prospective study over a period of seven years from $1^{\text {st }}$ January 2010 to $31^{\text {st }}$ December 2015 . A total of 52 patients who underwent a laparoscopic hysterectomy were recruited at the teaching hospital of Yopougon-Abidjan. Results: The mean age was 50.2 years $( \pm 3.9$ years) (36-62 years). The average parity was 3 . Few patients had undergone anterior pelvic surgery for either myomectomy or caesarean section. Uterine fibroid was the major surgical indication with a rate of $61.54 \%$. The average size of the uterus was $12 \mathrm{~cm}(8-18 \mathrm{~cm})$. Total hysterectomies type II and III with or without adnexectomy were essentially performed with rates of $28.85 \%$ and $32.69 \%$, respectively. Sometimes it was associated with a lymphadenectomy or a colpo-suspension. The average length of a hysterectomy is 170 minutes (87-385 minutes). Four cases of laparo-conversions have been noted. Blood loss was approximately 95 $\mathrm{ml}( \pm 12 \mathrm{ml})$ with a maximum of $300 \mathrm{ml}$. The complications were mainly two digestive wounds and a bladder fistula. The average length of hospital stay is three days apart from any complication.

Conclusions: The laparoscopic approach is less painful, is associated with less blood loss, shorter hospital stay, faster recovery, fewer complications, and better care. A training period of surgeons associated with the equipment of the health structures is necessary to popularize this procedure surgical.
\end{abstract}

Keywords: Complications, Hysterectomy, Laparoscopy surgical, Uterine fibroids

\section{INTRODUCTION}

Laparoscopy is a modern surgical technique that began in 1940 with Raoul Palmer. ${ }^{1}$ Firstly, in gynecology, she subsequently invested and upset all fields of surgery. In principle, it consists in operating in the abdominal cavity without making a wide parietal opening unlike laparotomy. The operative field is displayed on a screen connected to a fine optics passed through the abdominal wall and connected to a light source. ${ }^{1}$ The development of laparoscopic surgery has considerably modified the management of uterine and adnexal diseases., ${ }^{2,3}$ Hysterectomy is one of the most common procedures in India, the incidence of hysterectomy is 4 to $6 \%$, of which $90 \%$ are for benign indications. While the incidence of hysterectomy in Western countries is 10 to $20 \%, 75000$ hysterectomies would have been performed in France, in 2002; 660,000 in the United States. Until 1990, the standard approaches surgical were laparotomy and the vaginal route. ${ }^{4,5}$ The improvement of the material, the 
operative comfort due to the video and to the anesthetic techniques made the hysterectomy accessible to the laparoscopic approach. The first laparoscopic hysterectomy procedure is reported by Reich in $1989 .{ }^{2}$ It presents its risks and benefits. Due to its noninvasiveness, the reduction of postoperative morbidity, the aesthetic benefit, the magnified vision of the operative field, the accuracy and efficiency of surgical procedures, the laparoscopic approach is now a good alternative for practitioners. $^{1,4,6}$

Long carried out in northern countries where several works have been reported, its use remains limited in low income countries because of the lack of equipment related to its high cost and consequently the absence of practitioners trained in this surgical technique. The main aim of this work is to report the experience of the use of this endoscopic pathway in the management of benign diseases of the uterus of Ivorian women and more specifically, to specify the operative indications, to describe the various operative techniques, indicate the length of intervention and hospital stay and describe the operative complications observed.

\section{METHODS}

\section{Framework, type and period of study}

A prospective descriptive study conducted over 7 years from $1^{\text {st }}$ January 2010 to $31^{\text {st }}$ December 2015 , which took place in Abidjan at the Obstetrics and Gynecology Department of the University Hospital Center (CHU) of Yopougon.

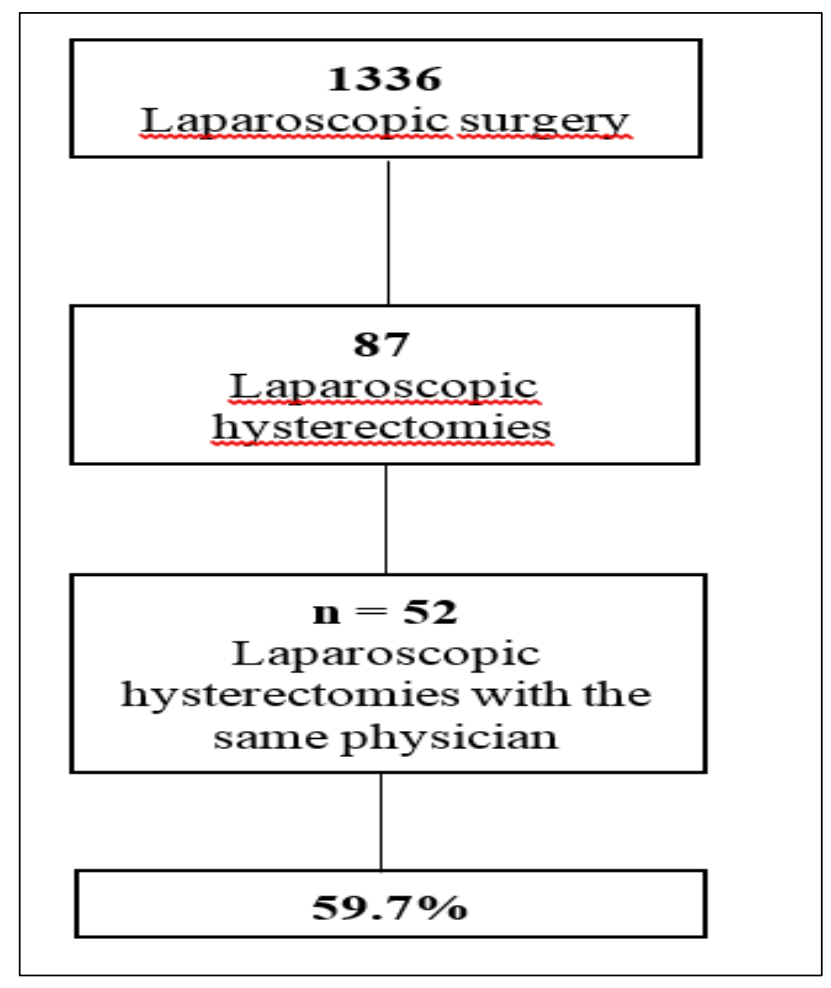

Figure 1: Sampling procedure.

\section{Population}

Women with hysterectomy indications for benign uterine diseases (uterine hemorrhagic fibroids, uterine adenomyosis, dysplastic lesions of the cervix and endometrium) were included with their informed consent. Women whose uterine volume exceeded an estimated size of $18 \mathrm{~cm}$, or with an antecedent history more than two previous pelvic surgery or whose operative record was unavailable have been not selected. A continue series of 52 laparoscopic hysterectomies performed by the same physician on 87 in the hospital

\section{Procedure}

\section{Equipment}

We have a laparoscopy column, forceps and laparoscopies scissors, bipolar current forceps and a monoplary current forceps. For the vaginal exposure or uterus mobilization, we commonly used a system made of forceps of pozzy on which is secured a uterine cannula or a uterine manipulator that facilitates this gesture made by the second assistant (Figure 2).

Four trocars are used: one under or umbilical $10 \mathrm{~mm}$ in diameter and three other suprapubic $5 \mathrm{~mm}$ in diameter.

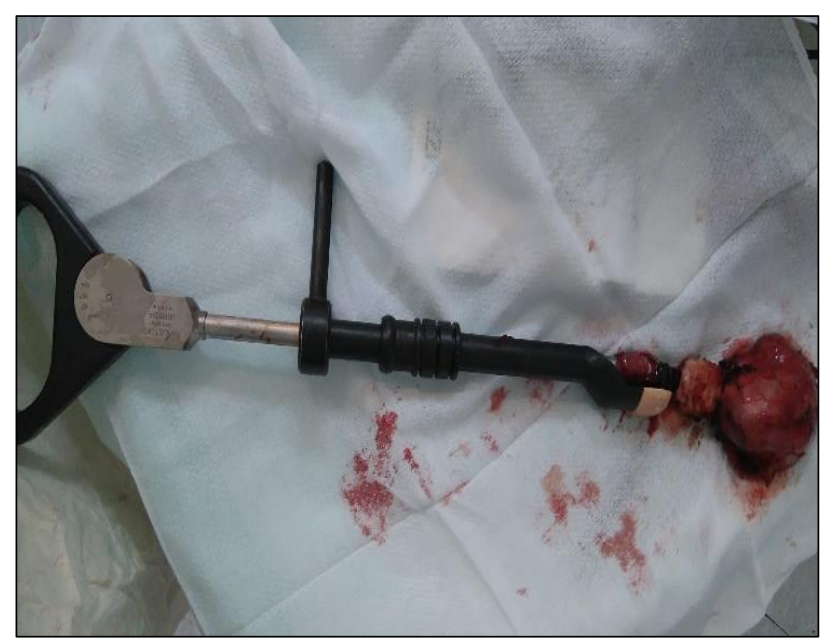

Figure 2: Uterine manipulator and uterus after total laparoscopy hysterectomy.

\section{Surgical team}

The surgical procedure was performed by the same surgeon. He was a senior surgeon with expertise in endoscopic gynecological surgery, assisted by gynecologic surgeons (6) who had trained in laparoscopic surgery.

A team of physicians (2) and nurse anesthetists (2) performed alternatively pre-anesthetic consultations and anesthesia of patients. 


\section{Preparation and installation of the patient}

On admission a colonic preparation was made by enema with dihydrogenophosphate of sodium the day before or 12 hours before surgery. The patient is placed on the operating table in the supine position and secondarily in the Trendelenburg position after general anesthesia. The surgeon stands on the left, an assistant opposite and the second assistant between the legs of the patient carrying out the vaginal manipulation of the uterus.

\section{Surgical procedure}

We perform pneumoperitoneum using Palmer's needle followed by the introduction of trocars. The choice of the surgical procedure varies according to the per-operative findings. The classification of the American Association of Gynecologic Laparoscopists (AAGL) distinguishes 4 types of intervention according to the level of dissection performed laparoscopically. ${ }^{2,8}$

Type I or "vaginal hysterectomy assisted by laparoscopy includes haemostasis and the section of the adnexal pedicles and round ligaments, releasing the apex of the broad ligament, facilitating movement through the natural pathways.

Type II associates vesico-uterine dissection and section of the uterine pedicles.

Type III performs intra-facial dissection of the cervix, haemostasis of the cervicovaginal pedicles and begins the vaginal opening.

Type IV involves complete laparoscopic hysterectomy, including vaginal opening and closing. The only time of "vaginal route " is the extraction of the piece., ${ }^{2,7-9}$

Large uteri with difficult mobilization impose the Types I or II. To date due to the failure of the uterine manipulator, we frequently perform Types II or III. In the presence of adhesion, a first time of adhesiolysis by coagulation or divergent traction is performed facilitating the exposure of the operative field. Extraction of large uteri is by scissor hemisection or vaginal and morcellation. Pelvic drainage is not systematic. It is carried out in case of operational difficulties related to adhesions, for which the adhesiolysis leaves persistent bleeding. The drain is removed on the 2 nd postoperative day. When we perform a Type I or II hysterectomy, a second laparoscopy check of the haemostasis, the integrity of the ureters is systematic.

\section{Immediate postoperative follow-up}

The venous route was withdrawn as soon as the transit was resumed. Patients were left fasting the night of the procedure. A semi-liquid diet was offered to them the next morning. Normal feeding was allowed as soon as the transit was resumed. The exit was allowed on average on the second or third day under analgesic treatment, heparin therapy. The dressings of the cutaneous incisions were made until complete cicatrization two weeks later.

\section{Variables}

The main parameters studies were: the type of laparoscopic hysterectomy, the indications, the size of the uterus, the blood loss, the complications, the length of surgery and the length of hospital stay.

\section{Data analysis}

The data were collected by a single investigator using a questionnaire by browsing the medical record of hospitalization including the operative reports. Survey data were entered in Excel and analyzed with Epi-Info 6.04

\section{RESULTS}

\section{Epidemiological features}

The mean age was 50.2 years ( \pm 3.9 years) (36-62 years). $55.26 \%$ of them had over 50 years old.

The average parity was $3.25 \%$ of the cases, had undergone anterior pelvic surgery either for myomectomy or caesarean section.

Table 1: Distribution of 52 surgical procedures according to operative indications, size of the uterus and type of hysterectomy.

\begin{tabular}{|c|c|c|}
\hline & Effective (n) & Rate $(\%)$ \\
\hline \multicolumn{3}{|l|}{ Indications } \\
\hline Endometrial hyperplasia & 8 & 15.40 \\
\hline Adnexal mass & 2 & 3.84 \\
\hline Adénomyosis & 7 & 13.46 \\
\hline Uterine fibroids & 32 & 61.54 \\
\hline CIN3 & 3 & 5.76 \\
\hline \multicolumn{3}{|c|}{ Size or uterus centimetre $(\mathrm{cm})$} \\
\hline$\leq 10$ & 13 & 25.00 \\
\hline$>10-14 \leq$ & 32 & 61.54 \\
\hline$>14$ & 7 & 13.46 \\
\hline \multicolumn{3}{|c|}{ Type of hysterectomy AAGL* } \\
\hline Type I & 9 & 17.31 \\
\hline Type II & 15 & 28.85 \\
\hline Type III & 17 & 32.69 \\
\hline Type IV & 11 & 21.15 \\
\hline Total & 52 & 100 \\
\hline
\end{tabular}

* American Association of Gynecologic Laparoscopists

Uterine fibroids were the major indication of hysterectomies. Type III hysterectomies constituted the majority of the type of intervention performed. The average size of the uterus was $12 \mathrm{~cm}(8-18 \mathrm{~cm})$ (Table 1). Hysterectomies with or without adnexectomy were performed. Sometimes gestures were associated 
including: three pelvic lymphadenectomies and four colpo-suspensions. 11 cases of pelvic adhesions with 4 postoperative complications were noted. 4 laparoconversions were practiced. The large size $(18 \mathrm{~cm})$ of the uterus preventing treatment of the uterine pedicles, the presence of a large fibroid of $18 \mathrm{~cm}$, for which all attempts at vaginal and laparoscopic morcellation failed, dense pelvic adhesions hampering any progression due to a history of myomectomy motivated the conversion. Blood loss was estimated approximately $95 \mathrm{ml}( \pm 12 \mathrm{ml})$ with a maximum of $300 \mathrm{ml}$.

\section{Length of surgery and hospital stay}

The average length of surgery was 170 minutes $( \pm 27 \mathrm{~mm})$ (87-385 mm). The mean length of hospital stay was 3.28 days ( \pm 0.59 days).

\section{DISCUSSION}

\section{Epidemiological features}

Fibroids account for $62 \%$ of indications in black women compared with $29 \%$ for Caucasian women. ${ }^{6,10}$ It is most often young women, whose evaluation of the low operative risk was carried out by an anesthesia consultation associated with a request for properly targeted complementary examinations. We carried out hysterectomies on a female population whose average age was fifty years, in menopause or pre-menopause. Women with pregnancy project were excluded after the gynecological consultation. These are patients with an average parity of three children. According to Debodinance, the rate of hysterectomy increases with parity. ${ }^{10}$

\section{Operative indications}

The feasibility of laparoscopic hysterectomy is definitively acquired and performed by several teams. ${ }^{2,11,6}$ The problem now is to specify the place and the modalities of this technique compared to other surgical possibilities. ${ }^{12}$ Until the early 1990 s, there were only two ways to perform a hysterectomy: the abdominal and vaginal routes. Despite all the benefits of vaginal surgery on laparotomy, an analysis of the literature clearly shows that most hysterectomies are performed through the abdominal wall. ${ }^{13,4}$ Multicentric analyzes, which reflect the modalities performed in daily practice, show that, on average, only $30 \%$ of hysterectomies are performed vaginally. ${ }^{4,13}$ Two parameters are essential for the choice of the laparoscopic approach:

Vaginal accessibility; It is capital, especially when there is a vaginal time; the narrowness of the vagina would limit the gestures. The vaginal examination will also verify if the uterus is mobile. Vaginal deliveries would improve vaginal compliance. ${ }^{2,8}$ The average parity of our patients was 3 and allows a mobile uterus with a small size for almost all of our patients.
The size of the uterus, although it is easy for experienced surgeons to extract large uteri vaginally, the abdominal wall route would be preferable. ${ }^{2,4,8}$ His assessment was made by clinical and ultrasound examination. The average size was $12 \mathrm{~cm}(6-18 \mathrm{~cm})$ in the present study. Mélis A in France, had a size of the uterus of $13.3 \mathrm{~cm}$, (9$17.6 \mathrm{~cm})$ in the type I hysterectomy laparoscopies and $9.7 \pm 5.2 \mathrm{~cm}$ for Nieboer TE in the Netherlands. ${ }^{4,12}$ Beyond that, we observed difficulties in mobilizing and therefore exposure of the uterus. The extraction of the uterus is by hemisection or parceling.

For other authors, referring to comparative studies on vaginal and laparoscopic hysterectomy, uterine weight was a decision-making factor of the approach. The greater the weight, the less the vaginal route was possible. The average weight of the uterus was for Niebor, Wattiez, 215 \pm 154 grams and 264.8 $\pm 133.6 \mathrm{~g}$ for Mueller A. ${ }^{12,14,15}$

The immediate pre-operative examination in the operating room under anesthesia was also a fundamental decision-making element for us, although the final decision is for the first endoscopic exploration. The cervical traction test with the Pozzi forceps after disinfection confirms the mobility and the absence of parietal adhesion of the uterine fundus in case of parietal scar. The existence of a history of abdominopelvic surgery (caesarean section, myomectomy, etc.) was not a major factor in the choice of the endoscopic approach. This is shared by some authors. ${ }^{6,8}$

The laparoscopies field would allow a panoramic view facilitating the adhesiolyses first. For other researchers, however, the surgeon's experience was associated with the choice of the laparoscopic approach.5,11 For other gynecologists, a uterus larger than $12 \mathrm{~cm}$, nulliparity with few mobile uterine, anterior pelvic surgery (endometriosis, adhesion) narrowness of the vagina, lack of mobility of the vagina, uterus without access to the uterine vessels, obesity, cancer are all contraindications..$^{8,16}$

Indications are mainly benign pathologies of the uterus. Our indications are similar to that of many teams that have produced long series. Massimo et al in Milan, Italy, Holub $\mathrm{Z}$ in the Republic $\mathrm{C}$, Rouen $\mathrm{H}$ in France, uterine fibroid constitutes about $50.3 \%$ of hysterectomies. ${ }^{17,12}$ In our series, uterine fibroids and adenomyosis constitute $74 \%$ of this intervention. Cervical intraepithelial neoplasia III (CIN III) of the cervix were indications of the endoscopic approach. These are indications shared by several teams in various other countries. ${ }^{5,17-19}$

Long carried out used for the benign pathology, the original works spread the field of laparoscopic surgery to malignant pathologies. Pellegrino A in Italy Bettaiah in India, did not observe any major difficulty in laparoscopic staging of endometrial cancer of the endometrium. ${ }^{19}$ 


\section{Type of hysterectomy}

The American Association of Gynecologic Laparoscopists (AAGL) has reported four types of laparoscopic hysterectomies based on the level of uterine supportive treatment in the pelvic area..$^{2,5,9,15,18}$ In France, Chapron $\mathrm{C}$ and Dubuisson JB, estimate that in practice there are only two large groups of laparoscopic hysterectomies according to haemostasis of the uterine pedicle. ${ }^{2}$ They consider, as initially defined by Reich in 1989, that a laparoscopic hysterectomy if the haemostasis of the uterine vessels is performed by the endoscopic route. When the haemostasis of the uterine pedicles is done by the vaginal route, these are not considered like laparoscopic hysterectomies. The indications are different for each of these two categories of hysterectomy. ${ }^{8}$ According to the American classification we had frequently performed type II or III hysterectomies. When the size of the uterus is greater than $12 \mathrm{~cm}$ with difficulty of exposure and not easy dissections, we have done the type III. Type IV was booked for uteri of small size, easily mobilized. The vaginal suture by laparoscopic pathway was easy.

We noted simple hysterectomies associated or not with the conservation of the appendices. Laparoscopic surgery can also allow to stage a cervical cancer, lymph node dissection, a surgical management for the early stages of ovarian cancer. ${ }^{18-23}$ The advantage of the laparoscopic approach is to be non-traumatic with the reduction of the adherential risk, at the cost of a long operating time. ${ }^{21,24}$

\section{Length of surgery}

The average length of surgery was 170 minutes $( \pm 27 \mathrm{~mm})$ (87-385 mm). Kirsten in Holland reported an average time of 122 minutes and Mueller A in Germany $114.0 \pm 33.8 \mathrm{~min}^{24,14}$ They have state-of-the-art equipment such as electrosurgery, electric morcellators that significantly reduce operator time. ${ }^{6,7,24}$ Several factors have lengthened the operating time: the initial adhesiolysis sometimes in cases of pelvic adhesions, the large sizes of the uterus and the associated gestures.

\section{Laparo-conversion}

There is a probability of laparo-conversion (abdominal wall route) for overcoming any difficulty or complication during the procedure preventing continuation of the laparoscopic approach. On a series of 173 hysterectomies Ghosh D, has reported 2.2\% conversion. ${ }^{25}$ Makinen J, and Abdollah about $1.8 \%$ from 2000 to 2003 out of 597 hysterectomies. ${ }^{26,27}$ They observed a constant decrease in the conversion rate due to the best control of this surgical technique. A multicenter study on vaginal and laparoscopic hysterectomy reported by Gauthier in France in 2015 noted in a multivariate analysis that obesity (OR $=3.11,95 \%$ CI: $1.25-7.77, p=0.01$ ), previous history of pelvic surgery $(\mathrm{OR}=2.82,95 \% \mathrm{CI}$ : 1.21-6.57, $\mathrm{p}=0.02)$ and uterine weight $\geq 500 \mathrm{~g}(\mathrm{OR}=$
3.86, 95\% CI: 1, 46-10.3, $\mathrm{p}=0.01$ ) were significantly associated with the risk of laparo-conversion. ${ }^{28} \mathrm{We}$ performed conversions due to severe adhesions and a large uterine size.

\section{Blood loss}

They are minimized in laparoscopy because of the use of bipolar coagulation forceps for dissection and tissue excision. Various studies evaluate $200 \mathrm{ml}$ blood loss. ${ }^{5,6}$ They are still minimal in Type IV interventions. We observed an average blood loss of 100-150 ml. Blood loss was high in type III hysterectomies during the vaginal stage.

\section{Morbidity}

Several authors have distinguished two types of complications: minor complications including fever, bower obstruction and bladder wound and major complications including hemorrhages, postoperative bladder fistulas, ureteral wounds and perforations of the rectum. These complications vary from $1.8 \%$ to $3.3 \%$ for minor forms of 0.5 to $1 \%$ for major forms. ${ }^{2,3,11,26,29}$ Lesions of the urinary tract (bladder and urethra) are the most common visceral lesion encountered in laparoscopic hysterectomy. The bowel lesions are rare and usually thermal. The section of the uterine artery by laparoscopy is the most common gesture that may increase the risk of ureteral injury, especially if the surgeon is not experienced. ${ }^{5,11}$

We observed, among other things, a bladder fistula in a patient with a history of two cesarean sections who had pelvic pain four days after surgery. A laparoscopy highlighted a vesical fistula linked to a fall of eschar. The final repair was done with urologist team. The bladder suture and ureteral catheterization were performed. Bladder wounds are the most common and treated with laparoscopic sutures and an indwelling bladder catheter for about ten days. ${ }^{26,29}$ Body mass index (BMI) $\geq 30$ $\mathrm{kg} / \mathrm{m}^{2}$, history of pelvic surgery, history of caesarean section and uterine weight $\geq 500 \mathrm{~g}$ (NP4) are risk factors for complication of benign hysterectomy. ${ }^{28}$

\section{Length of hospital stay}

The average length of hospital stay was 3.28 days $( \pm 0.59$ days), it can be short of 2 days and this outside of per or postoperative complications. Of all the studies, the Length of hospital stay is similar. The absence of invasive gestures, the slightest manipulation of the digestive loops justify this fact. ${ }^{11,12,27}$ Our long hospitalization was mainly related to bladder wounds.

\section{CONCLUSION}

The laparoscopic approach is less painful, is associated with less blood loss, shorter hospital stay, faster recovery, fewer complications, and better care for the women 
concerned. A period of training of surgeons associated with equipment of the health structures is necessary to popularize the procedure of exploitation.

\section{ACKNOWLEDGMENTS}

The authors would like to thank the foundation and the University of Felix Houphouet Boigny Abidjan-Cocody, University Hospital of Yopougon Abidjan.

\section{Funding: No funding sources}

Conflict of interest: None declared

Ethical approval: The study was approved by the Institutional Ethics Committee

\section{REFERENCES}

1. Botchorishvili R, Velemir L, Wattiez A, Tran X, Bolandard F, Rabischong BF, at al. Coelioscopy and laparoscopic surgery: general principles and instrumentation. EMC (Elsevier Masson SAS, Paris). Surgical Techniques Gynecol. 2007;14:515-41.

2. Chapron C, Dubuisson JB. Total hysterectomy for benign pathologies, coeliosurgical techniques and indications. Enc Med-Chir Surgical TechniquesGynecol. 1995;41-655.

3. Bonilla DJ, Lindsay M, Riz J, Crawford B. Total laparoscopic hysterectomy: Our 5 years' experience (1998-2002). Ochsner J Printemps. 2010;10(1):8-12.

4. Melis A, Buisson S, Lutz JM, Salvat J. Factors for the choice of the hysterectomy approach for benign uterine lesions (prolapse and excluded obstetric indications). J Gynecol Obstet Biol Reprod. 2005;34(1):241-51.

5. Kumar KR, Goyal M, Singla S, Bhagwan Sh J, Malhotra N, Kumar S. A prospective randomized study of total laparoscopic hysterectomy laparoscopically assisted vaginal hysterectomy and non-descent vaginal hysterectomy for the treatment of benign diseases of the uterus. Arch Gynecol Obstet. 2011;284:907-12.

6. Candiani M, Izzo S, Bulfoni A. Laparoscopic versus vaginal hysterectomy for benign pathology. Am J Obstet Gynecol. 2009;200:368.e1-368.e7.

7. Bourdel N, Tran X, Botchorhisvili R, Pouly JL, Canis M, Mage G. Laparoscopic hysterectomy in ten steps. J from Chirur. 2009;146(5):483-91.

8. Reich H. Total laparoscopic hysterectomy: indications, techniques and outcomes. Cur Opin Obstet Gynecol. 2007;19(4):337-44.

9. Olive DL, Parker WH, Cooper JM, Levine RL. The AAGL classification system for laparoscopic hysterectomy. J Am Assoc Gynecol Laparoscopist. 2000;7(1):9-15.

10. Debodinance P. Hysterectomies for benign lesions on non-prolapsed uterus: epidemiology and postoperative follow-up in the North of France. J Gynecol Obstet Biol Reprod. 2001;30:151-9.

11. Donnez O, Jadoul P, Squifflet J, Donnez J. A series of 3190 laparoscopic hysterectomies for benign disease from 1990 to 2006: evaluation of complications compared with vaginal and abdominal procedures. BJOG. 2009;116:492-500.

12. Nieboer TE, Spaanderman MEA, Bongers MY, Kirsten VBK. Gynecologists estimate and experience laparoscopic hysterectomy as more difficult compared with abdominal hysterectomy. Gynecol Surg. 2010;7:359-63.

13. Roman H, Zanati J, Friederich L, Resch B, Lena E, Marpeau L. Laparoscopic hysterectomy of large uterine with uterine artery coagulation at its origin. JSLS. 2008;12:25-9.

14. Wattiez A, Soriano D, Fiaccavento A, Canis M, Botchorishvili R, Pouly J, et al. Total laparoscopic hysterectomy for very enlarged uteri. J Am Assoc Gynecol Laparosc. 2002;9(2):125-30.

15. Mueller A, Renner SP, Haeberle L, Lermann J, Oppelt P, Beckmann MW, et al. Comparison of total laparoscopic hysterectomy (TLH) and laparoscopyassisted supracervical hysterectomy (LASH) in women with uterine leiomyoma. Eu J Obstet Gynecol Reprod Biol. 2009;144(1):76-9.

16. Deffieuxa X, Rochambeaub B, Chênec G, Gauthierd T, Huetd S, Lamblinc G, et al. Hysterectomy for benign pathology: recommendations for clinical practice. J Gyn Obst et Biol de la Reprod. 2015;44:1219-27.

17. Zdenek H, Jabor A, Sprongl L, Kliment L, Fischlova D, Urbanek S. Surgically induced hormonal, metabolic and inflammatory changes in laparoscopic hysterectomy: a comparison with abdominal hysterectomy. Gyn Endoscopy. 2002;11(5):299-304.

18. Pomel C, Rouzier R. Laparoscopic enlarged colpohysterectomy: technique and operational difficulties. radical hysterectomy. Enc Med Chir (Elsevier SAS, Paris), Techniques chirurgicales Gynécologie. 2005:41-731.

19. Bettaiah R, Reddy CA. Laparoscopic hysterectomies: our 10 years experience in a single laparoscopic center. J Obstet Gynecol India. 2016;66(4):274-81.

20. Pellegrino A, Signorelli M, Fruscio R, Villa A, Buda A, Beretta P, et al. Feasibility and morbidity of total laparoscopic radical hysterectomy with or without pelvic lymphadenectomy in obese women with stage I endometrial cancer. Arch Gynecol Obstet. 2009;279(5):655.

21. Kasia JM, Njamen TN, Raiga J, Calmet P, Medou A, Messima R, et al. Laparoscopic hysterectomy in Africa in a series of 48 cases. $\mathrm{J}$ de la SAGO. 2006;7(1):26-30.

22. Querleu D, Ferron G, Leblanc E. Lomboaortic lymphadenectomy in gynecological cancers. EMCObstet Gynecol. 2005;2(2):137-43.

23. Thavaramara $T$, Sheanakul C, Hanidhikul $P$, Ratchanon S, Wiriyasirivaj B, Leelahakorn S. Results of laparoscopic pelvic and/or para-aortic lymphadenectomy in gynecologic oncology patients in Bangkok Metropolitan Administration Medical College and Vajira Hospital. J Med Assoc Thai. 2008;91(5):619-24. 
24. Kluivers KB, Ten Cate FA, Bongers MY, Brölmann HA, Hendriks JC. Total laparoscopic hysterectomy versus total abdominal hysterectomy with bilateral salpingo-oophorectomy for endometrial carcinoma: a randomized controlled trial with 5-year follow-up. Gynecol Surg. 2011;8(4):427-34.

25. Ghosh D, Wipplinger P, Byrne DL. Can total laparoscopic hysterectomy replace total abdominal hysterectomy? a 5-year prospective cohort study of a single surgeon's experience in an unselected population. Gyn Surg. 2013;10(2):109-15.

26. Mäkinen J, Johansson J, Tomás C, Tomas E, Heinonen PK, Laatikainen T,et al. Morbidity of 10 110 hysterectomies by type of approach. Hum Reprod. 2001;16(7):1473-8.

27. Abdollahi SF, Bahlouli A, Mostafa PG, Rasooli S, Morteza G. Comparison of laparoscopy-assisted hysterectomies with conventional hysterectomies. Saudi Med J. 2009;30(6):813-6.

28. Gauthiera T, Hueta S, Marcellib M, Lamblinc G, Chênec G. Hysterectomy for benign pathology: choice of the approach, vaginal suture technique and morcellation: recommendations. J Gyn Obst Biol Reprod. 2015;44:1168-82.

29. Hoffman CP, Kennedy J, Borschel L, Burchette R, Kidd A. Laparoscopic hysterectomy: the Kaiser Permanente San Diego experience. J Min Inv Gynecol. 2005;12(1):16-24.

Cite this article as: Koffi KA, Aka KE, Fomba M, Seni K, Horo A, Kone M. African experiences of laparoscopic hysterectomy about a continuous series of 52 cases by the same practitioner: indications, surgical procedures and complications. Int J Reprod Contracept Obstet Gynecol 2018;7:789-95. 